\title{
Nirsevimab: An Extended Half-life Monoclonal Antibody for the Prevention of Infant Respiratory Syncytial Virus Infection
}

\author{
Joseph B Domachowske \\ Department of Pediatrics, SUNY Upstate Medical University, Syracuse, NY, USA
}

$\mathrm{R}$ espiratory syncytial virus (RSV) infection is a major cause of respiratory tract infections in infants and young children and remains the leading cause of hospitalization among those less than 1 year of age. On a global scale, it is estimated that 3.4 million infants develop severe RSV disease and that as many as 253,000 children under 5 years of age die from the infection every year. Decades of effort to develop a safe and effective active vaccine have been unsuccessful. Moreover, available treatment modalities are limited to supportive interventions, such as hydration, delivery of supplemental oxygen, and when necessary, invasive mechanical ventilation. Pharmacologic interventions aimed at preventing severe RSV infection using passive immunization have been more successful but, to date, are used only for disease prevention in very high-risk infants. Palivizumab, a humanized RSV monoclonal antibody has been the mainstay for infant RSV prevention among specific high-risk infants for more than two decades. While its efficacy is well established, its relatively short halflife requires that it be administered monthly during periods of exposure. New extended half-life monoclonal antibodies are now showing favourable results in clinical trials. One of these new investigational extended half-life monoclonal antibodies, nirsevimab, has already advanced to phase III clinical trials. The aim of this review is to summarize the characteristics of nirsevimab and describe the promising results from the pivotal phase IIb efficacy trial.

\section{Keywords}

Respiratory syncytial virus, immunoprophylaxis, nirsevimab, passive immunization

Disclosure: Joseph B Domachowske has no financial or non-financial relationships or activities to declare in relation to this article.

Review process: Double-blind peer review.

Compliance with ethics: This study involves a review of the literature and did not involve any studies with human or animal subjects performed by the author.

Authorship: The named author meets the International Committee of Medical Journal Editors (ICMJE) criteria for authorship of this manuscript, takes responsibility for the integrity of the work as a whole, and has given final approval for the version to be published.

Access: This article is freely accessible at touchRESPIRATORY.com (c) Touch Medical Media 2021.

Received: 13 December 2021

Accepted: 1 March 2021

Published online: 31 August 2021

Citation: touchREVIEWS in Respiratory \& Pulmonary Diseases. 2021;6(1):38-41

Corresponding author: Joseph B Domachowske,

SUNY Upstate Medical University, Department

of Pediatrics, 750 East Adams Street, Syracuse

NY, 13210, USA. E: domachoj@upstate.edu

Support: No funding was received for

the publication of this article.
Respiratory syncytial virus (RSV) is a ubiquitous virus that causes annual epidemics of infection in young children in all parts of the world. In temperate regions, epidemics are seasonal, and predictable during the winter months. Approximately half of all infants develop their first RSV infection prior to their first birthday. By 24 months of age, almost all children are infected by RSV. ${ }^{1-4}$ Re-infection is common throughout life, with the first infection typically being the most severe. The virus causes an upper respiratory tract infection that progresses to lower airway disease in 25$40 \%$ of infants and young children. ${ }^{1-4}$ Young infants who develop lower respiratory tract infections (LRTIS) frequently require hospitalization, as it is not unusual for young infants with RSV bronchiolitis or pneumonia to develop respiratory rates of 80 breaths per minute or higher, hypoxaemia and/ or dehydration secondary to an inability to feed..$^{1-3}$ Rates of infant RSV hospitalization are highest during the first 3 months of life. In the USA and Europe, 1-3\% of the birth cohort is hospitalized with RSV each year, while rates in other areas of the world, such as Brazil and Guatemala, reach as high as 5-6\%. Hospitalization rates for infants born prematurely are consistently higher. ${ }^{4}$ The global burden of severe disease is substantial, estimated at 3.4 million infants annually. The aim of this review is to summarize the characteristics of nirsevimab and describe the promising results from the pivotal phase IIb efficacy trial.

Although several clinical trials to test novel treatment modalities are underway, ${ }_{1}^{5-8}$ the current standard of care for the treatment of RSV infection is limited to supportive care. ${ }^{9}$ While RSV bronchiolitis is a wheezing illness, bronchodilators and glucocorticoids have not been shown to impact the disease course in a clinically meaningful way. Ribavirin, an antiviral medication once used to treat infants hospitalized with RSV infection, is no longer used for the same reason. In the absence of effective therapeutics, any and all efforts at disease prevention become increasingly important.10,11

In the 1960s, the early and first efforts to develop an active RSV vaccine failed miserably when RSVnaive infants, who received the formalin-inactivated investigational vaccine, experienced severe enhanced RSV disease rather than being protected from infection. ${ }^{12,13}$ Two of the infants died. Now, more than 50 years later, advances in virology, protein chemistry, immunology and vaccinology have finally led to new and promising active vaccination strategies for study in human trials. While a detailed discussion regarding the progress in investigational active RSV vaccine development is beyond the scope of this review, excellent summaries have been published elsewhere. ${ }^{14-17}$

The development of an active vaccine for the prevention of infant RSV infection remains a global priority, but the World Health Organization estimates that it will be at least 5-10 years until 
Table 1: Relative risk reduction in favour of nirsevimab for medically attended lower respiratory tract infection by gender, age at enrolment and gestational age at birth ${ }^{35}$

\begin{tabular}{|c|c|c|c|c|c|}
\hline \multirow[b]{2}{*}{ Population subgroup } & \multicolumn{2}{|l|}{ Placebo } & \multicolumn{2}{|l|}{ Nirsevimab } & \multirow[b]{2}{*}{ Relative risk reduction, $\%(95 \% \mathrm{Cl})$} \\
\hline & Subjects, n & LRTIS, n (\%) & Subjects, n & LRTIS, n (\%) & \\
\hline Female & 224 & $24(11)$ & 468 & $9(2)$ & $82(62-92)$ \\
\hline Male & 260 & $22(9)$ & 501 & $16(3)$ & $62(29-80)$ \\
\hline Age $\leq 3$ months & 257 & $22(9)$ & 516 & $7(1)$ & $84(63-93)$ \\
\hline Age $>3-6$ months & 153 & $16(11)$ & 320 & $13(4)$ & $61(21-81)$ \\
\hline Gestational age 29-32 weeks & 165 & $18(11)$ & 326 & $9(3)$ & $75(45-88)$ \\
\hline Gestational age $>32$ weeks & 299 & $25(8)$ & 606 & $15(3)$ & $70(45-84)$ \\
\hline
\end{tabular}

$\mathrm{Cl}=$ confidence interval; $\mathrm{LTRI}=$ lower respiratory tract infection.

one or more are approved for routine clinical use..$^{10}$ In the meantime, RSV disease prevention must be emphasized. Anticipatory guidance to caregivers should include information about the modes and potential sources of transmission, and the seasonal epidemiology of the virus, with an emphasis on good hand hygiene and avoidance of day-care or other prolonged periods of repeated exposure to other children where possible. 1,10,18,19 Such education is especially important for the caregivers of the highest-risk infants, such as those born prematurely, those with chronic lung disease and those born with haemodynamically significant heart disease. Compared with term infants, those born prematurely are at higher risk of developing respiratory tract infections, including RSV, due to their highly immature immune systems, suboptimal transfer of maternal transplacental antibodies prior to birth and their smaller, less developed airways. , $10,20-23^{2}$

Passive immunization has been shown to be highly effective in preventing severe RSV infections in high-risk infants..$^{10}$ Palivizumab, a humanized monoclonal antibody, is currently the only US Food and Drug Administration (FDA)-approved passive prophylaxis for severe RSV LRTI in certain high-risk children. The product is approved for use among infants born at $\leq 35$ weeks' gestational age, and children $<24$ months of age with either haemodynamically significant congenital heart disease or chronic lung disease of prematurity. ${ }^{10,24}$ The safety and efficacy of palivizumab for prevention of RSV infection in these and other infant populations are well established through randomized, placebo-controlled trials and postlicensure (phase IV) effectiveness studies. ${ }^{24-26}$

Despite its excellent safety profile and clearly defined efficacy in preventing severe RSV infection in every cohort studied, the use of palivizumab in clinical practice has been generally limited to those at the very highest risk for severe disease. ${ }^{9,27,28}$ Such groups include only the most extremely premature infants ( $<29$ weeks gestational age) entering their first RSV season and those infants with heart disease or chronic lung disease. ${ }^{29,30}$ Between 8 and $12 \%$ of infants in these highestrisk groups require hospitalization for RSV infection. ${ }^{31}$ Use of passive prophylaxis outside of these high-risk groups is limited due to a restrictive RSV passive prophylaxis policy guidance from the American Academy of Pediatrics, high cost, and the short half-life of palivizumab requiring monthly dosing to maintain ongoing protective levels. ${ }^{1,11,24}$

\section{Extended half-life monoclonal antibodies for prevention of respiratory syncytial virus: nirsevimab}

Nirsevimab is a recombinant human monoclonal antibody that targets the pre-fusion conformation of the RSV F-protein by binding to the highly conserved site 0 of the pre-fusion RSV protein. The parent antibody was modified in two ways. The first series of modifications were made across the Fab (fragment, antigen-binding) portion of the antibody to optimize neutralizing activity across a broad range of group A and B RSV isolates. The details of those changes are proprietary. The second series of changes included a three amino acid substitution in the antibody's Fc (fragment, crystallizable) region, referred to as a YTE modification. Specifically, the native methionine (M) at position 252 was changed to tyrosine $(\mathrm{Y})$, the native serine $(\mathrm{S})$ at position 254 was changed to threonine ( $T$ ), and the native threonine ( $T$ ) at position 256 was changed to glutamic acid (E). Such an M252Y/S254T/T256E, or YTE modification, of any immunoglobulin G (IgG)k1 results in a half-life extension from $21-28$ days to $87-117$ days. ${ }^{32}$ During the development of nirsevimab, the combined changes were anticipated to result in a highly potent and broad-spectrum RSV-neutralizing activity with an extended half-life. Pharmacodynamic modelling studies suggested that administration of a single, fixed intramuscular dose to infants could provide protection from RSV infection for at least 5 months, the length of a typical RSV season. . $22,33^{2}$

After a phase I human clinical trial (ClinicalTrials.gov Identifier: NCT02114268) of nirsevimab in healthy adults demonstrated a comparable safety profile with placebo, the extended half-life monoclonal antibody was given fast-track designation by the FDA. ${ }^{32-34}$ Results from a single-dose, randomized, placebo-controlled, phase $\| \mathrm{b}$ study (ClinicalTrials.gov Identifier: NCT02878330) in preterm infants born at 29-35 weeks' gestational age (nirsevimab $n=969$; placebo $n=484$ ) demonstrated that the incidence of medically attended RSV LRTI was $70.1 \%$ lower with nirsevimab prophylaxis than with placebo, and the incidence of LRTI RSV hospitalization was $78.4 \%$ with nirsevimab prophylaxis than placebo. ${ }^{35}$ Subgroup analyses performed to evaluate relative risk reduction for medically attended LRTI according to the subject's gender, age at enrolment and gestational age at birth were each in favour of nirsevimab (Table 1). The highest percentage risk reductions were observed among those born between 29 and 32 weeks' gestational age, and those who were enrolled during their first 3 months of life. Types and rates of adverse events and non-RSV LRTIs were similar between those receiving nirsevimab and those receiving placebo.35,36 Table 2 provides a comparison of the frequency of specific adverse events reported in both placebo and nirsevimab recipients. Currently, nirsevimab is being further evaluated in a randomized, blinded, palivizumab-controlled phase II/ III trial among preterm infants and infants with chronic lung disease of prematurity or congenital heart disease (ClinicalTrials.gov Identifier: NCT03959488), and in a phase III, randomized, placebo-controlled trial that includes healthy late-preterm and term infants entering their first RSV 
Table 2: Adverse effects reported in recipients of placebo compared with recipients of nirsevimab ${ }^{35}$

\begin{tabular}{|l|l|l|}
\hline Adverse events & $\begin{array}{l}\text { Placebo }(\mathrm{n}=479) \\
\mathrm{n}(\%)\end{array}$ & $\begin{array}{l}\text { Nirsevimab (n=968) } \\
n(\%)\end{array}$ \\
\hline Diarrhoea & $50(10.4)$ & $100(10.3)$ \\
\hline Fever & $64(13.4)$ & $111(11.5)$ \\
\hline Bronchiolitis & $55(11.5)$ & $96(9.9)$ \\
\hline Gastroenteritis & $46(9.6)$ & $122(12.6)$ \\
\hline Lower respiratory tract infection & $53(11.1)$ & $86(8.9)$ \\
\hline Nasopharyngitis & $94(19.6)$ & $164(16.9)$ \\
\hline Rhinitis & $50(10.4)$ & $111(11.5)$ \\
\hline Upper respiratory tract infection & $170(35.5)$ & $395(40.8)$ \\
\hline Skin and soft tissue disorders & $110(23.0)$ & $237(24.5)$ \\
\hline Serious adverse events* & $81(16.9)$ & $108(11.2)$ \\
\hline Adverse events of special interest ${ }^{\dagger}$ & $3(0.6)$ & $5(0.5)$ \\
\hline Deaths ${ }^{\ddagger}$ & $3(0.6)$ & $2(0.2)$ \\
\hline
\end{tabular}

*None of the serious adverse events were considered to be related to the study drug by the site investigators.

${ }^{+}$All of the reported adverse events of special interest from both the placebo and nirsevimab recipients (total $n=8$ ) were considered to be related to the study drug by the site investigators. These events included hypersensitivity reactions, immune complex disease and thrombocytopenia.

FTwo deaths reported in the placebo group were caused by pneumonia, one was caused by a pericardial effusion. One death reported in the nirsevimab group was caused by congenital pulmonary vein stenosis. The second death, from an unknown cause, occurred during the night in an infant who was well when put down to sleep.

season (ClinicalTrials.gov Identifier: NCT03979313). 10,37,38 Table 3 provides a summary comparing key characteristics of palivizumab with nirsevimab.

Another investigational, extended half-life, monoclonal anti-F RSV antibody, MK-1654, is also being evaluated in a similarly designed phase II clinical trial (ClinicalTrials.gov Identifier: NCT03524118). ${ }^{39-41}$ Like nirsevimab, the YTE modifications of the Fc portion of MK-1654 extend its half-life to approximately 70-85 days. Fab modifications of MK-1654 have also been made, but are proprietary.

\section{Conclusion}

The published safety and efficacy data for nirsevimab for the prevention of infant RSV infection when administered as a single fixed dose offer the potential to change the landscape of infant RSV disease. To realize its full potential to reduce the morbidity, mortality and misery caused by infant
Table 3: Comparison of select characteristics of palivizumab and nirsevimab

\begin{tabular}{|c|c|c|}
\hline & Palivizumab & Nirsevimab \\
\hline Biologic source & Mouse & Human \\
\hline IgG subclass & Monoclonal IgG1 & Monoclonal IgG1 \\
\hline Modifications & Humanized & $\begin{array}{l}\text { YTE half-life extension } \\
\text { technology }\end{array}$ \\
\hline Serum half-life & 19-27 days ${ }^{42}$ & $59.3 \pm 9.6$ days $^{36}$ \\
\hline Antibody target & RSV F-protein & $\begin{array}{l}\text { Pre-fusion RSV F-protein } \\
\text { antigenic site } 0\end{array}$ \\
\hline FDA status & Approved 1998 & $\begin{array}{l}\text { Breakthrough drug } \\
\text { designation; ongoing phase } \\
\text { IIl studies }\end{array}$ \\
\hline $\begin{array}{l}\text { Target population for } \\
\text { receipt }\end{array}$ & $\begin{array}{l}\text { High-risk premature infants } \\
\text { experiencing their first RSV } \\
\text { season. } \\
\text { Children with chronic lung } \\
\text { disease of prematurity } \\
\text { experiencing their first or } \\
\text { second RSV season. } \\
\text { Children with ongoing } \\
\text { haemodynamically } \\
\text { significant heart disease } \\
\text { experiencing their first or } \\
\text { second RSV season }\end{array}$ & $\begin{array}{l}\text { All infants experiencing } \\
\text { their first RSV season. } \\
\text { Children with chronic lung } \\
\text { disease of prematurity } \\
\text { experiencing their first or } \\
\text { second RSV season. } \\
\text { Children with ongoing } \\
\text { haemodynamically } \\
\text { significant heart disease } \\
\text { experiencing their first or } \\
\text { second RSV season }\end{array}$ \\
\hline $\begin{array}{l}\text { Route of } \\
\text { administration }\end{array}$ & Intramuscular & Intramuscular \\
\hline Dose & $15 \mathrm{mg} / \mathrm{kg}$ & $\begin{array}{l}\text { Fixed at 50, } 100 \text { or } 200 \text { mg } \\
\text { based on weight range }\end{array}$ \\
\hline $\begin{array}{l}\text { Frequency of } \\
\text { administration }\end{array}$ & Monthly during RSV season & Once per RSV season \\
\hline
\end{tabular}

FDA = US Food and Drug Administration; $I g G=$ immunoglobulin $G ; R S V=$ respiratory syncytial virus.

RSV infection on a global scale, cost, production and availability must align with the capacity, need and demand from a broad spectrum of global stakeholders. Such stakeholders include, but are not limited to, the World Health Organization and the public health systems they support; the manufacturer; and the layers of infrastructure needed to distribute, store and deliver the passive immunization to the world's birth cohort each year. $\square$
1. Respiratory syncytial virus. In: Kimberlin DW, Brady MT, Jackson MA, eds. Red Book: 2018-2021 Report of the Committee on Infectious Diseases. 31st ed. Elk Grove Village, IL: American Academy of Pediatrics. 2018:682-92.

2. Jain S, Williams DJ, Arnold SR, et al. Community-acquired pneumonia requiring hospitalization among U.S. children. N Eng/ J Med. 2015;372:835-45.

3. Leader S, Kohlhase K. Respiratory syncytial virus-coded pediatric hospitalizations, 1997 to 1999. Pediatr Infect Dis J. 2002;21:629-32.

4. Anderson EJ, DeVincenzo JP, Simões EAF, et al. SENTINEL1: Two-season study of respiratory syncytial virus hospitalizations among U.S. infants born at 29 to 35 weeks' gestational age not receiving . In fants born at 29 to 35 weeks' gestational age not

Xing Y Proesmans M. New therapies for acute RSV infections: where are we? Eur J Pediatr. 2019;178:131-8.

6. Ralston SL, Lieberthal AS, Meissner HC. Clinical practice guideline: the diagnosis, management, and prevention of bronchiolitis. Pediatrics. 2015:134:e1474-502.

7. Fearns R, Deval J. New antiviral approaches for respiratory syncytial virus and other mononegaviruses: inhibiting the RNA polymerase. Antiviral Res. 2016;134:63-76.

8. Nicholson EG, Munoz FM. A review of therapeutics in clinical development for respiratory syncytial virus and influenza in children. Clin Ther. 2018;40:1268-81.

9. American Academy of Pediatrics Committee on Infectious Diseases; American Academy of Pediatrics Bronchiolitis Guidelines Committee. Updated guidance for palivizumab prophylaxis among infants and young children at increased risk of hospitalization for respiratory syncytial virus infection. Pediatrics. 2014:134:415-20.

10. Simoes EAF, Bont L, Manzoni P, et al. Past, present and future approaches to the prevention and treatment of respiratory syncytial virus infection in children. Infect Dis Ther 2018;7:87-120

11. Resch B. Product review on the monoclonal antibody palivizumab for prevention of respiratory syncytial virus infection. Hum Vaccin Immunother. 2017;13:2138-49.

12. Kapikian AZ, Mitchell RH, Chanock RM, et al. An epidemiologic study of altered clinical reactivity to respiratory syncytial (RS) virus infection in children previously vaccinated with an inactivated RS virus vaccine. Am J Epidemiol. 1969:89:405-21.

13. Kim HW Canchola $G$ Brandt $C D$, et al. Respiratory syncytial virus disease in infants despite prior administration of antigenic Virus disease in infants despite prior administration of
inactivated vaccine. Am J Epidemiol. 1969:89:422-34.

14. Wright M, Piedimonte G. Respiratory syncytial virus prevention and therapy: past, present, and future. Pediatr Pulmonol and therapy: past,

15. Mazur NI, Higgins D, Nunes MC, et al. The respiratory syncytial virus vaccine landscape: lessons from the graveyard and promising candidates. Lancet Infect Dis. 2018;18:e295-311.

16. Rossey I, Saelens X. Vaccines against human respiratory syncytial virus in clinical trials, where are we now? Expert Rev Vaccines. 2019;18:1053-67.

17. Vaccine Resource Library and PATH website. RSV vaccine and mAb snapshot. Available at: https://vaccineresources.org/ details.php?i=1562 (accessed 16 March 2021)

18. Glezen WP, Taber $L H$, Frank AL, et al. Risk of primary infection and reinfection with respiratory syncytial virus. Am J Dis Child 1986;140:543-6.

19. Heikkinen $\mathrm{T}$, Valkonen $\mathrm{H}$, Waris $\mathrm{M}$, Ruuskanen $\mathrm{O}$. Transmission of respiratory syncytial virus infection within families. Open Forum Infect Dis. 2015;2:ofu118

20. Yeung CY, Hobbs JR. Serum-gamma-G-globulin levels in normal premature, post-mature, and "small-for-dates" newborn babies. Lancet. 1968;1:1167-70.

21. Gagneur A, Pinquier D, Quach C. Immunization of preterm infants. Hum Vaccin Immunother. 2015;11:2556-63.

22. Boyce TG, Mellen BG, Mitchel EF Jr, et al. Rates of hospitalization for respiratory syncytial virus infection among children in medicaid. J Pediatr. 2000;137:865-70.

23. Langston C, Kida K, Reed M, et al. Human lung growth in late gestation and in the neonate. Am Rev Respir Dis. 1984:129:607-13.

24. SYNAGIS [package insert]. Gaithersburg, MD: MedImmune LLC; 2017.

25. Anderson EJ, Carosone-Link P, Yogev R, et al. Effectiveness of palivizumab in high-risk infants and children: a propensity score weighted regression analysis. Pediatr Infect Dis J. 2017;36:699-704.

26. Blanken MO, Rovers MM, Molenaar JM, et al. Respiratory syncytial virus and recurrent wheeze in healthy preterm infants. N Eng/ J Med. 2013;368:1791-9.

27. Goldstein M, Phillips R, DeVincenzo JP, et al. National Perinata Association 2018 Respiratory Syncytial Virus (RSV) Prevention Clinical Practice Guideline: an evidence-based interdisciplinary collaboration. Neonatology Today. 2017;12:1-14. 
28. Goldstein M, Krilov LR, Fergie J, et al. Respiratory syncytial virus hospitalizations among U.S. preterm infants compared with term infants before and after the 2014 American Academy of Pediatrics guidance on immunoprophylaxis: 2012-2016. Am J Perinatol. 2018:35:1433-42.

29. Krilov LR, Fergie J, Goldstein M, et al. Impact of the 2014 American Academy of Pediatrics immunoprophylaxis policy on the rate, severity, and cost of respiratory syncytial virus hospitalizations

30. Kong AM, Krilov LR, Fergie J, et al. The 2014-2015 national impact of the 2014 American Academy of Pediatrics guidance for respiratory syncytial virus immunoprophylaxis on preterm infants born in the United States. Am J Perinatol. 2018;35:192-200.

31. Piedimonte G. RSV infections: state of the art. Cleve Clin I Med. 2015;82(11 Suppl. 1):S13-8

32. Griffin MP, Khan AA, Esser MT, et al. Safety, tolerability, and pharmacokinetics of MEDI8897, the respiratory syncytial virus prefusion F-targeting monoclonal antibody with an extended half-life, in healthy adults. Antimicrob Agents Chemother. 2017;61:e01714-16.
33. US National Library of Medicine. Nirsevimab. Available at: https://chem.nlm.nih.gov/chemidplus/rn/1989556-22-0 (accessed 16 March 2021).

34. AstraZeneca PLC. US FDA grants Breakthrough Therapy AstraZeneca PLC. US FDA grants Breakthrough Therapy
Designation for potential next-generation RSV medicine Designation for potential next-generation RSV medicine
MEDI8897 [press release]. 2019. Available at: www.astrazeneca. MEDI8897 [press release]. 2019. Avallable at: Www.astrazentmedia-centre/press-releases/2019/us-fda-grants-
com breakthrough-therapy-designation-for-potential-next-generation rsv-medicine-medi8897.html\#! (accessed 16 March 2021).

35. Griffin MP, Yuan Y, Takas T, et al. Single-dose nirsevimab for prevention of RSV in preterm infants. N Eng/ J Med. 2020;383:415-25.

36. ClinicalTrials.gov. A study to evaluate the safety and efficacy of MEDI8897 for the prevention of medically attended RSV LRT in healthy preterm infants. (MEDI8897 Ph2b) [NCT02878330] 2018. Available at: https://clinicaltrials.gov/ct2/show/ NCT02878330 (accessed 16 March 2021).

37. Clinicaltrials.gov. A study to evaluate the safety of MEDI8897 for the prevention of medically attended respiratory syncytial virus (RSV) lower respiratory track infection (LRTI) in high-risk Virus (RSV) lower respiratory track infection (LRTI) in high-risk
children [NCT03959488]. 2019. Available at: https://clinicaltrials
gov/ct2/show/NCT03959488 (accessed 16 March 2021).

38. ClinicalTrials.gov. A study to evaluate the safety and efficacy of MEDI8897 for the prevention of medically attended RSV LRTI in healthy late preterm and term infants (MELODY) [NCT03979313]. 2019. Available at: https://clinicaltrials.gov/ct2/ [NCTO3979313]. 2019. Available at: https://Clinicats
show/NCT03979313 (accessed 16 March 2021).

39. Aliprantis A, Wolford D, Caro L, et al. A randomized, doubleblind, placebo-controlled trial to assess the safety and tolerability of a respiratory syncytial virus (RSV) neutralizing monoclonal antibody (MK-1654) in healthy subjects. Presented at: IDWeek 2018, San Francisco, CA, USA, 6 October, 2018. Poster 1971.

40. ClinicalTrials.gov. Safety, tolerability, and pharmacokinetics of MK-1654 in infants (MK-1654-002) [NCT03524118]. 2019. Available at: https://clinicaltrials.gov/ct2/show/NCT03524118 (accessed 16 March 2021).

41. Maas B, Aliprantis A, Wolford D, et al. RSV monoclonal antibody (MK-1654) phase 1 pharmacokinetics (PK) in healthy adults and population PK modeling to support pediatric development. Presented at: IDWeek 2018, San Francisco, CA, 3-7 October, 2018. Poster 1384 